\title{
Study of Socio-Demographic Profile of Pesticidal Poisoning Cases in Tertiary Care Center
}

\author{
Bhandari $B^{1}$, Saxena $P^{2}$, Khadka $D^{3}$
}

\begin{abstract}
Introduction: The pesticide poisoning is a common medical emergency and leads to increase morbidity and mortality rate in developing countries due to easy accessibility and low cost. The study was conducted to study the socio-demographic profile of poisoning case to understand the possible factors responsible for poisoning episodes. Method: A hospital based descriptive crosssectional study was carried out in Nepalgunj Medical College, Teaching Hospital, Kohalpur, a tertiary care center, conducted for period of six months from October 2017 to March 2018.The socio-demographic profile of all cases of pesticidal poisoning attended in emergency department or admitted in medical ward were collected on a suitably designed pre- structured proforma and analyzed. Results: Total 164 patients were enrolled in the study. Majority were fallen in the age group of 20-30 years with female $76.80 \%$ dominating the male $23.20 \%$. Married couples $(74.40 \%)$ were found to be more affected and house wife was more vulnerable group $42.10 \%$. Incidence of poisoning was more common in joint family as compare to nuclear family $81.10 \%$ versus $18.90 \%$.Organophosphorous was most common pesticides $42.70 \%$ and suicide was main manner of poisoning. Quarrel with spouse was main reason in majority $23.80 \%$ and most of events were held at evening $69.50 \%$. Conclusion: Pesticide poisoning was common in developing countries. More emphasis should be given on preventive measures and safety practices among the population for prevention and reduction of the pesticide poisoning.
\end{abstract}

Key words: Organophosphorous, pesticides, poisoning, socio-demographic profile, tertiary care center

\section{INTRODUCTION}

Acute poisoning is an important medical emergency and major global health problem with significant morbidity and mortality affecting people of all age groups. According to World Health Organization, (WHO) poisoning occurs when people drink, eat, breathe, inject, or touch enough of a hazardous substance (poison) to cause illness or death ${ }^{1}$. As per WHO data in year 2012 it was reported that more than $90 \%$ of fatal poisoning cases are seen in middle and low income countries i.e. the developing countries in general and agricultural countries in particular ${ }^{2}$. Pesticide is any substance or mixture of substances intended for preventing, destroying, repelling or mitigating any pest. Pesticide poisoning is an important health problem particularly in the low-income countries like developing countries.

The reported incidence of pesticide poisoning worldwide is about 3 million and suicidal cases accounts more than one third $^{3,4}$. Pesticide poisoning is common in our countries as majority of population's likely hood of living is still farming. Factors contributing pesticidal poisoning are, easy availability,

\footnotetext{
1. Dr. Binus Bhandari

2. Dr. Prem Saxena

3. Dr. Dipendra Khadka
}

\section{Address for correspondence:}

Dr.Binus Bhandari

Department of Forensic Medicine

Nepalgunj Medical College \& Teaching Hospital

Kohalpur, Banke, Nepal

Email:binusbhandari3@gmail.com low coast, lack of proper knowledge regarding proper handling and storage along with poverty, ignorance and illiteracy. Information regarding pesticidal poisoning in our region is limited and hence this study was carried out to study the sociodemographic profile of pesticidal poisoning in this center which will be useful for enhancement of the knowledge, awareness and safety practices among the population for prevention and reduction of the pesticide poisoning.

\section{MATERIAL AND METHODS}

The present study was undertaken at Nepalgunj Medical College, teaching hospital a tertiary care center. A descriptive cross sectional study was conducted for period of six months from October 2017 to March 2018. All cases of pesticidal poisoning attended in emergency department or admitted in medical ward were included in the study. Cases of food poisoning, adverse drug reaction, insect bites, snake bites and other than pesticides were not included in the study.

Patient data relevant to the study was obtained from treatment charts/case sheets, laboratory reports and patient or patient's relative. The relevant information was collected on a suitably designed pre- structured proforma. The socio-demographic profile consists of age, gender, occupation, marital state, and educational status, manner of poisoning and cause of poisoning. The collected data were entered in Microsoft Excel software and data analysis was performed with the help of SPSS software version 20.0 .

\section{RESULTS}

Total of 164 patients enrolled majority were fell in the age 
group of $20-30$ years $39 \%$ (64). Total female $76.80 \%$ (126) dominating the male $23.20 \%$ (38). Religion wise almost all 99.40 (163) were Hindus. Incidence of poisoning was found more common among married couples $74.40 \%$ (122) versus $25.60 \%$ (42) in unmarried. Most of the victims had completed secondary level education $48.80 \%$ (80). Incidence of poisoning was more common in joint family as compare to nuclear family
(81.10\% versus $18.90 \%)$. House wife was more vulnerable group $42.10 \%$ (69) as compared to others. Organophosphorous was most common pesticides used for poisoning $42.70 \%$ (70) and suicide was main manner of poisoning. Quarrel with spouse was main reason for poisoning in majority $23.80 \%$ (39) and majority of events were held at evening $69.50 \%(114)$.

\begin{tabular}{|c|c|c|}
\hline Variables & Frequency & Percent \\
\hline \multicolumn{3}{|l|}{ Age group } \\
\hline$<20$ Yrs & 35 & $21.30 \%$ \\
\hline $20-30$ & 64 & $39.00 \%$ \\
\hline $30-40$ & 36 & $22.00 \%$ \\
\hline $40-50$ & 15 & $9.10 \%$ \\
\hline $50-60$ & 6 & $3.70 \%$ \\
\hline$>=60$ & 8 & $4.90 \%$ \\
\hline Range (Years) & $13-73$ & \\
\hline Median age & $25 \pm 12.74$ & \\
\hline \multicolumn{3}{|l|}{ Gender } \\
\hline $\mathrm{F}$ & 126 & $76.80 \%$ \\
\hline$M$ & 38 & $23.20 \%$ \\
\hline \multicolumn{3}{|l|}{ Religion } \\
\hline Hindu & 163 & $99.40 \%$ \\
\hline Muslim & 1 & $0.60 \%$ \\
\hline \multicolumn{3}{|l|}{ Maritia IStatus } \\
\hline Married & 122 & $74.40 \%$ \\
\hline Unmarried & 42 & $25.60 \%$ \\
\hline \multicolumn{3}{|l|}{ Education } \\
\hline Graduates & 17 & $10.40 \%$ \\
\hline No formal education & 36 & $22.00 \%$ \\
\hline Primary education & 31 & $18.90 \%$ \\
\hline Secondary education & 80 & $48.80 \%$ \\
\hline \multicolumn{3}{|l|}{ Type of Family } \\
\hline Joint & 133 & $81.10 \%$ \\
\hline Nuclear & 31 & $18.90 \%$ \\
\hline \multicolumn{3}{|l|}{ Occupation } \\
\hline Business & 8 & $4.90 \%$ \\
\hline Farming & 13 & $7.90 \%$ \\
\hline House wife & 69 & $42.10 \%$ \\
\hline Service holder & 34 & $20.70 \%$ \\
\hline Student & 35 & $21.30 \%$ \\
\hline Unemployed & 5 & $3.00 \%$ \\
\hline
\end{tabular}

Table I: Sociodemographic details $(n=164)$ 


\begin{tabular}{|c|c|c|}
\hline Features & Frequency & Percentage \\
\hline \multicolumn{3}{|l|}{ Type of pesticides } \\
\hline Aluminium phosphide & 17 & $10.40 \%$ \\
\hline Cypermethrin & 19 & $11.60 \%$ \\
\hline Organophosphorous & 70 & $42.70 \%$ \\
\hline Unknown & 32 & $19.50 \%$ \\
\hline Zinc phosphide & 26 & $15.90 \%$ \\
\hline \multicolumn{3}{|l|}{ Manner of Poisoning } \\
\hline Accidental & 11 & $6.70 \%$ \\
\hline Suicidal & 153 & $93.30 \%$ \\
\hline \multicolumn{3}{|l|}{ Cause of Poisoning } \\
\hline Failure & 35 & $21.30 \%$ \\
\hline Miscellaneous & 34 & $20.70 \%$ \\
\hline Nil & 38 & $23.20 \%$ \\
\hline Quarrel with others & 18 & $11.00 \%$ \\
\hline Quarrel with spouse & 39 & $23.80 \%$ \\
\hline \multicolumn{3}{|l|}{ Time of ingestion } \\
\hline Afternoon & 1 & $0.60 \%$ \\
\hline Evening & 114 & $69.50 \%$ \\
\hline Morning & 10 & $6.10 \%$ \\
\hline Night & 39 & $23.80 \%$ \\
\hline
\end{tabular}

Table II: Distribution of cases according to features of poisoning ( $n=164)$.

\section{DISCUSSION}

Poisoning being an important public health problem. It consumes not only the valuable health service resources but also causes considerable morbidity and mortality. Sociodemographic factors behind it were assessed with an attempt to find out the factors responsible for ingestion of poison, which might be very helpful for making preventive strategies and early intervention. The present study shows that the highest number of patients belonged to the age group of 20 to 30 years $39 \%$ (64) with mean age of 25 years, which was comparable to other studies ${ }^{6,7}$. This age group belongs to those who are more active, both physically and mentally with having major responsibilities towards family and society having continuous financial crises and stressful life. Higher suicidal rate was found among females $76.80 \%$ (126) than males $23.20 \%$ (38) which was similar with study done by Pokhrel et $\mathrm{al}^{8}$. Majority were housewives by occupation $42.10 \%$ (69) and belongs to joint family $81.10 \%$ (133) The high incidence may be because females are more exposed to stress, strain, have to manage household activities with limited resources along with domestic violence, unemployment and behavioral problems also contribute higher incidence among females. Married couples were more vulnerable as compared to unmarried ( $74.40 \%$ versus $25.60 \%$ ) which was comparable to study done by Mugadlimath A et al ${ }^{9}$. Quarrel with spouse was main culprit in majority $23.20 \%$ (38) as compared with other factors. Marital disharmony probably causing stress and leading to extreme steps like poisoning. Among different pesticides used organophosphorous was used by majority $42.70 \%$.(70). OP as main pesticides was also reported by other studies, ${ }^{90,11}$. As Agriculture is the main occupation of the people in this region and organophosphorus was commonly used pesticide in this locality, which was cheap and easily available and accessible in market. In our study most of events were held during evening time $69.50 \%$ (114) contrast to Maharani et al, where mostly in day time ${ }^{12}$. The main reason during evening time may be most of family members were at home and any kind of dispute, quarrel may aggravate the situation.

\section{LIMITATIONS}

The small sample size and short duration of this study may be the main limitation factors affecting the results. Also, most of the cases were diagnosed on the basis of patient's history and clinical examination, while they were not confirmed with laboratory testing. 


\section{CONCLUSION}

Organophosphorous was the most commonly used poison due to its easy availability and accessibility. We suggest the government should regulate the import, manufacture, sale, transport, distribution and use of insecticides and pesticides with a view to prevent risk to human beings.

\section{REFERENCES}

1. World Health Organization. Poisoning [document on the internet]. 2010 [Cited 2010 Oct 30]. Available from: http://www.who.int/topics/poisons/en.

2. Ather NA, Ara J, Khan EA, Sattar RA, Durrani R. Acute organophosphate insecticide poisoning. J Surg Pak. 2008; 13: 71-4.

3. Moebus S, Bodeker W. Mortality of intentional and unintentional pesticide poisonings in Germany from 1980 to 2010. J Public Health Policy. 2015 May; 36(2):170-80.

4. Bertolote JM, Fleischmann A, Deaths from pesticide poisoning: a global response. The British Journal of Psychiatry.(2006) 189: 201-3.

5. Howlader Mar, Sardar MH, Amin MR, Morshed MG, Islam MS Uddin MZ et al. Clinico-Epidemiological Pattern of poisoning in a Tertiary Level Hospital J Dhaka Med Coll. 2008; 17(2) : 111-5.

6. Abubakar S, Githa K, Kiran N, Sreebala. A Study on Pattern of Poisoning Cases in a Tertiary Care Hospital, Bangalore. Indian Journal of Pharmacy Practice .2014; (1) :13-17.

7. Patil A, Peddawad R, Verma VCS, Gandhi H. Profile of Acute Poisoning Cases Treated in a Tertiary Care Hospital: A Study in Navi Mumbai. Asia Pac J Med Toxicol. 2014;3:36-40.

8. Pokhrel D, Pant S, Pradhan A, Mansoor S. A comparative retrospective study of poisoning cases in central, zonal and district hospitals. Kathmandu university journal of science, engineering and technology. 2008;1 (5): 40-48.

9. Mugadlimath A, Bagali MA, Hibare SR, Ingale DI, Gupta N, Bhuyyar C. Study of socio-demographic profile of poisoning cases at Shri BM Patil Medical College Hospital and Research Centre,Bijapur. Int j cur res re., 2012 ;04 (20): 80-84.

10. Bansal N, Uniyal N, Kashyap P V , Varma A A profile of poisoning in Uttarakhand ; Transworld Med. Jr. 2013;1(4):128-130. 12.

11. Dash S K, Raju A S, Mahanty M K, Patnaik K K, Mahanty S Sociodemographic profile of poisoning cases. JIAFM. 2005; 27 (3) 133-138.

12. Maharani B and Vijayakumari N. Profile of poisoning cases in a Tertiary care Hospital, Tamil Nadu, India. Journal of Applied Pharmaceutical Science. 2013; 3 (01):91-094. 